\title{
MEASURING SPLANCHNIC TISSUE OXYGENATION IN PRETERM NEONATES WITH NECROTIZING ENTEROCOLITIS USING MULTI-SITE NEAR INFRARED SPECTROSCOPY: A PILOT STUDY COMPARING TWO ABDOMINAL LOCATIONS
}

\author{
E.M.W. Kooi ${ }^{1}$, M.E. van der Laan ${ }^{1}$, J.B. Hulscher ${ }^{2}$, M. Schurink ${ }^{2}$, A.F. Bos ${ }^{1}$ \\ ${ }^{I}$ Neonatology, Beatrix Children's Hospital, University Medical Center Groningen, ${ }^{2}$ Pediatric Surgery, \\ University Medical Center Groningen, Groningen, The Netherlands
}

Background and aim: Various abdominal locations have been reported to be useful for measuring splanchnic oxygenation with near-infrared spectroscopy (NIRS). We aimed to assess agreement between NIRS measurements of two abdominal locations within preterm neonates with (suspected) Necrotizing Enterocolitis (NEC).

Methods: Preterm infants with NEC Bell's stage 1 or more were eligible. Tissue oxygen saturation was measured by multi-site NIRS infra-umbilical (intestinal: $\mathrm{r}_{\mathrm{int}} \mathrm{SO}_{2}$ ) and below the right costal arch (liver: $\mathrm{r}_{\text {liv }} \mathrm{SO}_{2}$ ). Agreement of measurements between both locations was assessed by comparing values of stable measurements during 1-hour periods twice the first day after diagnosis, using Wilcoxon-Signed-Ranks test, Spearman's correlation and Bland-Altman plot.

Results: Fourteen measurements of 7 patients were included. Clinical characteristics: median gestational age: 30.1 weeks (range: 25.7-34.7), median birth-weight: 1516 grams (740-2400), median postnatal age: 9 days (3-41). All but one child with CNS sepsis had NEC stage $2 . \mathrm{R}_{\text {int }} \mathrm{SO}_{2}$ (median 67\% (range: 47\%-85\%)) and $\mathrm{r}_{\mathrm{liv}} \mathrm{SO}_{2}$ (median 56\% (33\%-90\%)) were not statistically different $(p=0.3)$. Spearman's rho was 0.44 $(p=0.12)$. Bland-Altman plot showed wide limits of agreement (figure 1).

Figure 1: Bland-Altman Plot: $\mathrm{r}_{\text {int }} \mathrm{SO}_{2}$ versus $\mathrm{r}_{\text {liv }} \mathrm{SO}_{2}$

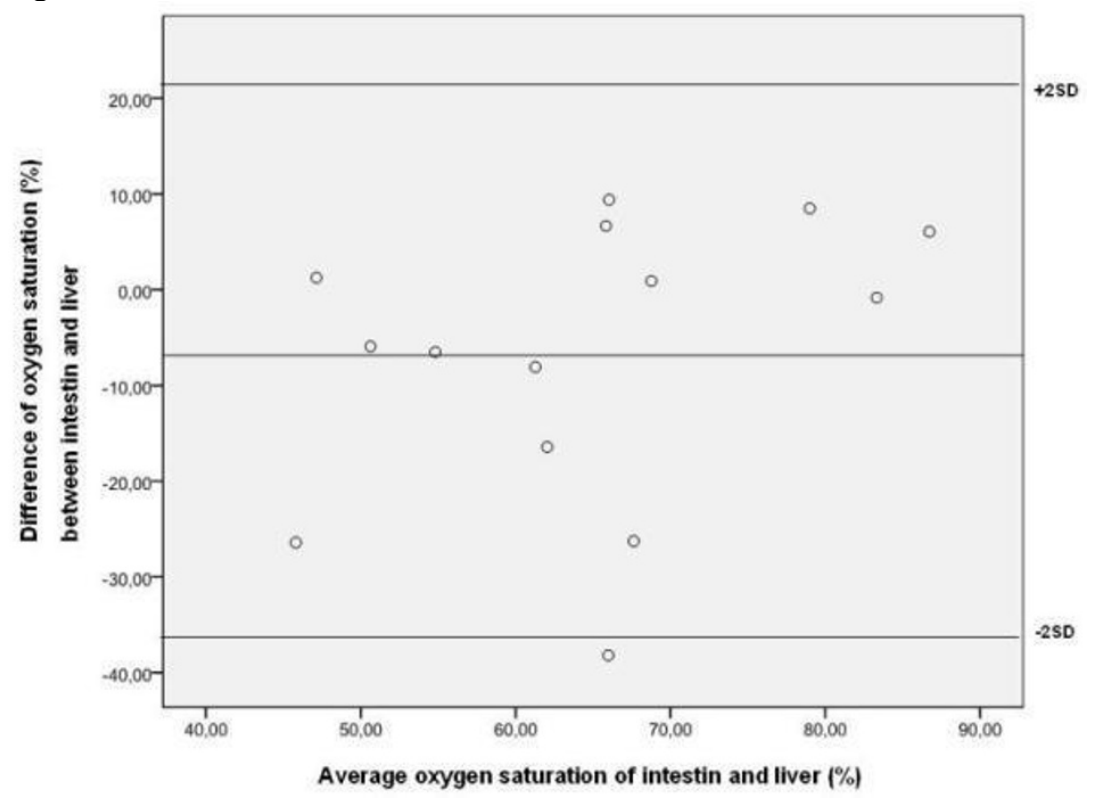

[Bland-Altman Plot: rintSO2 versus rlivSO2]

Conclusion: NIRS-measurements of intestinal and liver oxygenation values do not agree well in preterms with (suspected) NEC. Oxygenation values of these two locations can therefore not be randomly compared in clinical studies, and cannot substitute each other. 